\title{
Konsekuensi Transplantasi Hukum \\ terhadap Pancasila sebagai Norma Dasar dan Hukum Lokal
}

\author{
Hari Purwadi, Adriana Grahani Firdausy \\ Fakultas Hukum \\ Universitas Sebelas Maret Surakarta \\ h_purwadie@yahoo.com
}

\begin{abstract}
Legal transplants in the form of ideas, concepts, solutions or structures, institutions, and methods, from one country to another has been a tendency in the development of the law in various parts of the world. Including Indonesia, has conducted legal transplants from various foreign legal system or any other country in the formation of various laws. Legal transplants in the perspective of comparative law and culture has potential mismatch between law and society, considering foreign law (the model) has material base differ with the recipient, such as Indonesia, the material and social base reflected in the values of Pancasila or local law. Therefore, studies on this subject is very important, and in this study aims to analyze: (1) the form of transplantation of foreign law into the legal system of Indonesia (national law); (2) inevitability of legal convergence in the development of national law in the future. Theoretically, this study relates to theories of legal transplant or diffusion of law, in particular mixing legal system and harmonization or convergence. This study confirmed the legal transplant theories are constructed from practices in Western countries. For that purpose, this study methodologically used socio-legal research types (nondoctrinal / socio-legal research). Based on the category of Esin Örücü, found that legal transplants in Indonesia occurred in various combinations of the most complex forms to simpler. Constitution as an example, transplant in the form of structures, institutions, and methods, in addition to the form of ideas, concepts, and solusion from Western law, both civil law system and common law systems. Legal transplants in Indonesia generally more formal process (formal diffusion) rather than substantive and make Western law have a dominant position. Local law and Pancasila under pressure of Western law. Therefore, the development of the law in the future must be built on a foundation of Jurisprudence as activity of theorizing, so that ideas, concepts, and solutions, as well as structures, institutions, and methods that can be characterized Pancasila as Western law competitor.
\end{abstract}

Keywords: transplantation, harmonization, foreign laws, local laws, and Pancasila 


\begin{abstract}
Abstrak
Transplantasi hukum dalam bentuk ide, konsep, solusi atau struktur, institusi, dan metode, dari satu negara ke negara lain telah menjadi kecenderungan dalam pembangunan hukum di berbagai belahan dunia. Tidak terkecuali Indonesia, telah melakukan transplantasi hukum dari berbagai sistem hukum asing atau negara lain dalam pembentukan berbagai undang-undang. Transplantasi hukum dalam perspektif perbandingan hukum dan budaya (comparative law and culture) potensial melahirkan ketidaksepadanan antara hukum dan masyarakat (mismatch between law and society), mengingat hukum asing (model) memiliki basis materiil hukum dan sosial berbeda dengan tempat dipindahkan atau penerima (recipient), seperti Indonesia, yang basis materiil dan sosialnya tercermin dalam Pancasila atau hukum lokal. Untuk itu, studi mengenai hal ini sangat penting dilakukan, dan dalam penelitian ini bertujuan untuk menganalisis : (1) bentuk transplantasi hukum asing ke dalam tata hukum Indonesia (hukum Nasional); (2) keniscayaan kovergensi hukum dalam pembangunan hukum Nasional di masa datang. Secara teoritis, penelitian ini berhubungan dengan teoriteori transplantasi atau difusi hukum, khususnya pencampuran sistem hukum (mixing legal system) dan harmonisasi atau konvergensi hukum. Penelitian ini mengonfirmasi (confirming) teori-teori transplantasi hukum yang dibangun dari praktik-praktik di negara-negara Barat. Untuk tujuan itu, penelitian ini secara metodologis menggunakan jenis penelitian sosio-legal (nondoktrinal/socio-legal research), Dengan menggunakan kategori dari Esin Örücü, ditemukan bahwa transplantasi hukum di Indonesia terjadi dalam berbagai kombinasi bentuk dari yang paling kompleks sampai sederhana. Konstitusi sebagai misal, mentransplantasi dalam bentuk struktur, institusi, dan metode, di samping bentuk ide, konsep, dan solusi hukum Barat, baik civil law system maupun common law system. Transplanatsi itu secara umum lebih banyak dilakukan secara formal (difusi formal) daripada substantif dan menempatkan posisi dominan hukum Barat. Hukum lokal dan Pancasila mengalami tekanan dari Hukum Barat . Oleh karena itu, pembangunan hukum di masa datang harus dibangun di atas pondasi jurisprudence as activity of theorizing, sehingga ide, konsep, dan solusi, maupun struktur, institusi, dan metode yang berkarakter Pancasila dapat menjadi pesaing hukum Barat yang dominan.
\end{abstract}

Kata kunci: transplantasi, harmonisasi, hukum Asing, hukum lokal, dan nilai-nilai Pancasila

\title{
I. Pendahuluan
}

Tulisan ini bermaksud menjelaskan terjadinya pertemuan berbagai sistem hukum di Indonesia yang memengaruhi arsitektur hukum Nasional, bahkan posisi norma-norma hukum lokal dan Pancasila sebagai norma, filsafat, dan ideologis bangsa Indonesia. Transplantasi hukum (legal transplants) telah menjadi 
kecenderungan dalam pembangunan hukum di berbagai negara, termasuk di Indonesia, yang dilakukan dengan alasan yang berbeda-beda dalam setiap pembentukan hukum. Mulai dari upaya menyesuaikan dengan kecenderungan global atau internasional sampai fasilitasi perubahan ekonomi, teknologi, sosial, dan politik. Legal transpalnts dimaksud, yaitu the moving of a rule or a system of law from one country to another, or from one people to another - have been common since the earliest recorded history. (Alan Watson, 1993 : 21) Secara sederhana dapat juga diartikan "the transferring or borrowing of law between legal systems”. (Roger Cotterrell, 2006 :109)

Berbagai sistem bersaing, sehingga sistem kapitalis bukan satu-satunya yang menjadi aspirasi global. Persaingan itu untuk hegemoni global dengan sistem internasional negara, sistem global agama, sistem lingkungan global, dan sistem lainnya. (Sklair, dalam Larry Catá Backer, 2007 : 6) Hukum sebagai wadah kepentingan ekonomi maupun politik menerima konsekuensi membingkai persaingan sistem-sisitem yang bertemu itu, termasuk menghadapi pertemuan antar sistem hukum yang berbeda. Sistem hukum Eropa Kontinental (civil law system), common law system, sistem hukum islam, atau sistem hukum lokal (folk law) bertemu atau saling menyilang (reciprocal influences). Persilangan di antara sistem hukum di Indonesia juga tidak sama dalam setiap peraturan perundangundangan. Seperti dikatakan oleh von Benda-Beckmann, Keebet von BendaBeckmann, dan Anne Griffiths dengan mengutip pendapat McGrew bahwa :

As in the general literature on globalization, the analysis of the effects of globalization of law is usually situated at the nexus of national, international and transnational levels. This idea of a single site of legal sovereignty embodied in the state is undermined by patterns of global legal interaction which erode the boundaries between domestic and international law, foreign and domestic legal systems and practices, as well as internal and external juridical authorities.” (Franz von BendaBeckmann, Keebet von Benda-Beckmann, dan Anne Griffiths, 2005 : 4)

Pertemuan hukum itu dapat muncul dalam berbagai wujud melalui transplantasi hukum, baik karena alasan-alasan pembangunan atau reformasi hukum melalui penggunaan (sub)- sistem asing, maupun hubungan timbal-balik antara dua negara atau lebih, seperti perdagangan, juga pemanfaatan tenaga ahli 
yang pemikiran hukumnya memiliki karakteristik hukum asing. Pertemuan (subsistem) hukum tersebut bukan tanpa akibat, namun menimbulkan persaingan, yang memungkinkan dominasi salah satu di antaranya atau setidak-tidaknya pencampuran di antara dua atau lebih subsistem hukum, yang menimbulkan fragmentasi dalam berbagai sistem hukum, baik itu civil law, common law, hukum islam dan sistem hukum lainnya. Indonesia tidak dapat disangkal telah menegaskan bahwa Pancasila menjadi pandangan hidup filsafat bangsa. (B. Arief Sidharta, tanpa tahun: 8) Dalam tingkatan norma dan nilai, hal ini berarti di Indonesia terjadi pertemuan antara norma-norma hukum lokal (adat), hukum Islam, serta Pancasila sebagai falsafah bangsa Indonesia di satu sisi dan sistem hukum asing dengan filsafat hukum Barat-nya di sisi lain.

Indonesia tidak dapat disangkal telah masuk dalam pusaran globalisasi. Artinya, konsekuensi-konsekuensi sebagai jurisdiksi tempat pertemuan berbagai sistem hukum terbuka lebar. Pertemuan berbagai tata hukum, bahkan sistem hukum itu sudah terjadi sejak terbentuknya negara Indonesia yang plural dengan berbagai hukum adat maupun hukum agama. Dalam konteks pembangunan atau reformasi hukum Nasional - dari tingkatan konstitusi sampai peraturan daerah, transplantasi hukum secara sukarela (voluntary reception) atau paksaan (imposed reception) telah sering dilakukan yang berasal dari berbagai hukum asing (foreign law) melalui perbandingan hukum (comparative law). Terutama ketika hukum dijadikan instrumen perubahan sosial (social change) di Indonesia, seperti peraturan perundang-undangan di bidang hak asasi manusia (HAM), yang menawarkan ide-ide, seperti persamaan, kesetaraan, kepemilikan, dan perwakilan.

Mengikuti pemikiran madzab sejarah, yaitu "hukum sebagai jiwa bangsa” (the law is located in the spirit of the people; the volkgeist), maka hukum memiliki basis sosial tertentu. Juga, sebagaimana "mirror theories of law and social change ", yang menjelaskan bahwa hukum itu cerminan masyarakatnya (law mirrors society), atau dalam beberapa aspeknya sesuai. (Roger Cotterrell, 2006: 109) Seperti bahasa, hukum masyarakat terwujud secara spontan dari jalan hidup masyarakat itu : budaya, tradisi, dan kebiasaannya - yang menunjukkan gambar dasar dari “kesadaran umum” (common consciousness) masyarakat suatu 
negara. (Raymond Wacks, 2009 : 238) Terdapat pandangan berbeda dan ekstrim, seperti Alan Watson dalam American Jornal of Comparative Law, yang menegaskan bahwa "there is no interesting relationship to be discovered between law and society or that law is radically insulated from economics, sociology, and politics”. (Roger Cotterrell, 2006: 110)

Dalam konteks pembangunan atau reformasi hukum Nasional dengan menempuh jalan transplantasi hukum, maka jiwa bangsa “asing” dipertemukan dengan jiwa bangsa Indonesia yang plural dan dikristalisasi atau dikonstruksi sebagai Pancasila. Jiwa bangsa Indonesia dan asing belum tentu memiliki persamaan signifikan yang bersifat historis, sehingga transplantasi hukum menjadi tidak bermasalah sama sekali.

Berdasarkan hal-hal tersebut, permasalahan yang penting untuk dikemukakan, yaitu : (1) bagaimanakah posisi hukum lokal dan nilai-nilai Pancasila dalam Tata Hukum Indonesia (hukum Nasional) yang dibangun dengan meminjam model asing, khususnya tradisi hukum Barat ?; (2) bagaimanakah kovergensi hukum dalam pembangunan hukum Nasional niscaya dilakukan ?

\section{Metode Penelitian}

Penelitian ini berpijak pada paradigma hukum di samping sebagai fakta, juga sebagai gugusan nilai, sebagaimana pandangan sosiologi normatif atau oleh Nonet disebut "normative or morally approach" dalam sosiologi hukum. Penelitian ini digolongkan ke dalam doktrin hukum (legal doctrine) sebagai “an empirical discipline”. Oleh karena itu, penelitian ini merupakan jenis penelitian sosio-legal atau nondoktrinal (socio-legal or nondoctrinal research).

Sebagai penelitian nondoktrinal atau sosio-legal, mengikuti pandangan bahwa studi sosio-legal dilihat sebagai alternatif interdisipliner. Sosio dalam studi sosio-legal tidak menunjuk pada sosiologi atau ilmu-ilmu sosial, tetapi merepresentasikan saling berhadapan dengan konteks tempat hukum itu berada. Oleh karena itu, penelitian ini merupakan penelitian kualitatif dengan tidak mengesampingkan peraturan perundang-undangan sebagaimana penelitian 
sosiologi hukum murni. Penelitian ini secara spesifik berkarakter perbandingan hukum kritis (critical comparative law).

\section{Posisi Pancasila dalam Tata Hukum Indonesia (Hukum Nasional) dengan Model Asing}

Konstitusi dan peraturan perundang-undangan lain sebagaimana diatur dalam Undang-Undang Nomor 12 Tahun 2011 tentang Pembentukan Peraturan Perundang-undangan (selanjutnya disingkat UU 12/2011) tidak dapat dilepaskan dari Pancasila. Sebab secara hukum, Pancasila telah diposisikan sebagai "sumber segala sumber hukum negara” (Pasal 2 UU 12/2011). Sumber hukum (source of law) secara konsepsional dapat dibedakan antara "law-sources" dan "lawfoundation-sources”(only with a plural “s”). (J. Paul Lomio, et all., 2011 : 2) "Law-sources" (sumber hukum) diartikan "something [such as a constitution, treaty, statute, or custom] that provides authority for legislation and for judicial decisions; a point of origin for law or legal analysis.” (Bryan A. Garner, ed., 2004 : 1429, bandingkan dengan J. Paul Lomio et all., 2011 : 2) Sedangkan “lawfoundation-sources" (sumber-dasar-hukum) diartikan "the science/knowledge on/of jurisprudence/origins of legal concepts and ideas”. (J. Paul Lomio et all., 2011 : 2) Dengan demikian, secara konsepsional, sumber hukum tidak terbatas pada peraturan perundang-undangan yang diatur dalam UU 12/2011 atau hukum negara (state law), namun meliputi juga sumber hukum tertulis atau tidak tertulis di luar yang diatur oleh UU 12/2011 serta ilmu hukum atau ilmu mengenai asalusul konsep-konsep dan ide-ide hukum. Ini berarti secara substansial, keseluruhan peraturan perundang-undangan, termasuk Konstitusi Indonesia seyogianya diderivasi dari Pancasila. Demikian pula sumber hukum di luar hukum negara juga sesuai dengan Pancasila. Dalam Penjelasan Pasal 2 UU 12/2011 dikemukakan dengan ungkapan "Menempatkan Pancasila sebagai dasar dan ideologi negara serta sekaligus dasar filosofis negara, sehingga setiap materi muatan peraturan perundang-undangan tidak boleh bertentangan dengan nilainilai yang terkandung dalam Pancasila.” Penjelasan Pasal tersebut hanya 
menyebut peraturan perundang-undangan atau hukum negara, meskipun sesungguhnya baik secara konseptual/teoritis maupun praktis, sumber hukum bukan hanya peraturan perundang-undangan atau hukum negara, namun juga norma-norma sosial lainnya, seperti hukum adat.

Berdasarkan Pasal 2 dan Penjelasan UU 12/2011 tersebut menandai bahwa UUD 1945 dan peraturan perundang-undangan lainnya secara substansial tidak disyaratkan diderivasi langsung dari ide dan konsep Pancasila. Namun, dapat dibawa atau dipindahkan dari sistem asing (foreign system), asalkan tidak bertentangan dengan Pancasila. Dalam hal inilah sesungguhnya muncul persoalan kesesuaian peraturan perundang-undangan, termasuk Konstitusi dengan Pancasila. Selama ini, pengujian peraturan perundang-undangan berhenti di satu sisi sampai pada batas pengujian peraturan perundang-undangan di bawah undang-undang terhadap undang-undang, dan di sisi lain pengujian undang-undang terhadap UUD 1945. Terkesan diterima begitu saja (taken for granted) bahwa UUD 1945 sesuai dengan/tidak bertentangan dengan Pancasila, meskipun terdapat mekanisme perubahan UUD 1945 sebagaimana diatur dalam Pasal 37 UUD 1945, yang menunjukkan perubahan pemaknaan terhadap Pancasila melalui UUD 1945. Oleh karena perubahan UUD 1945 secara prosedural bukan hal yang mudah, maka ketentuan-ketentuan atau prinsip dan norma dalam UUD 1945 niscaya menjadi cermin penuh dari Pancasila.

Lebih dari itu, dalam kenyataannya bahwa UUD 1945 merupakan cermin penuh dari Pancasila atau juga menampung model asing yang problematis dalam konteks hukum lokal dan Pancasila masih membutuhkan penjelasan. Hal ini berarti substansi peraturan peundang-undangan di bawah UUD 1945 masih problematis untuk memastikan bahwa Pancasila maupun hukum lokal mengambil bagian penting. Hal itu disebabkan transplantasi hukum telah menjadi cara penting dalam pembangunan hukum di Indonesia, sebagaimana juga dilakukan negara-negara lain. Upaya harmonisasi atas transplantasi tidak selalu berhasil seperti diharapkan, sehingga kemungkinan terjadi distorsi.

Dalam konsep harmonisasi hukum, Christopher Stuart mencontohkan kasus harmonisasi konteks Islam dan tradisi hukum Barat, menunjukkan ada 3 
(tiga) pengertian ; (1) sebagai adopsi bentuk sistem hukum lain; (2) sebagai integrasi melalui perjanjian antar negara; dan (3) sebagai konvergensi melalui pertemuan tujuan pengaturan yang sama. Bentuk pertama harmonisasi memerlukan suatu proses menetapkan hukum domestik identik dengan hukum negara lain. Ini berarti harmonisasi berbasis cara (means-based harmonization) dan biasanya dibuktikan melalui restrukturisasi hukum domestik, sehingga memasuki jalur hukum jurisdiksi lain. Hal ini lazimnya menghasilkan substitusi (penggantian) bentuk asli pada sistem legislasi asing, yang kebanyakan melahirkan divergensi. Bentuk kedua dari harmonisasi tidak mensyaratkan untuk meninggalkan atau menanggalkan sistem lokal. Namun, dilakukan modifikasi sistem-sistem lokal sebagai hasil negosiasi, sehingga semua negara yang berpartisipasi memilik saham. Harmonisasi ini dilakukan melalui konsensus, dan kadang-kadang dapat dilihat melalui integrasi persetujuan internasional, seperti kesepakatan GATT atau WTO, yang diundangkan sebagai jembatan antar sistem hukum. Ketiga, bentuk luas harmonisasi didasarkan pada suatu pendekatan kerangka kerja. Negara bekerja ke arah tujuan umum legislasi melalui modifikasi sistem masyarakat setempat untuk menghasilkan sesuai yang dikehendaki. Bentuk harmonisasi ini lebih banyak menghargai sistem masyarakat setempat. Berkebalikan dengan bentuk harmonisasi yang mensyaratkan keefektivan yang luas, yaitu hukum baru menyerupai bentuk rezim hukum yang di-copy. Fokusnya harmonisasi berbasis tujuan (ends-based harmonization), yaitu kesesuaian tujuan reformasi hukum dengan bentuk sistem masyarakat setempat. (Christopher Stuart, dalam Lary Cata Backer, 2007 : 281-282)

Indonesia tampaknya juga mengalami ketiga bentuk harmonisasi hukum itu. Permasalahannya, yaitu terjadi pengabaian terhadap hukum masyarakat setempat, seperti pada bentuk pertama mendominasi dalam pembangunan hukum di Indonesia. Dominasi tentu dalam tingkatan tertentu dapat berarti eliminasi, terutama dalam konsep atau struktur. Di samping itu, apabila bentuk kedua atau ketiga ditempuh dalam pembangunan hukum, secara teoritis, pertemuan institusi hukum atau sistem hukum itu tidak akan pernah menjadi suatu "tailor-made model”. Hal itu di antaranya disebabkan ketidaksepadanan (mismatch) dari kedua 
jiwa bangsa itu tidak dapat dielakkan (Esin Örücü, 2000 : 14) Dengan ungkapan lain, memunculkan paradoks akibat adanya diversitas di samping similaritas (kesamaan) antara sistem hukum penerima (host system, recipient) dan asal (home system, models). Di samping itu, memungkinkan terjadinya "kontaminasi” (contaminations), seperti terjadi di Uni Eropa. Sebagai contoh, dalam konteks Uni Eropa, konsep-konsep hukum “civilian” memasuki common law di Inggris pada tingkatan konsep, dan tidak pada tingkatan struktur dan teknik. Demikian pula di Hongkong, Common law sekarang dikelilingi oleh hukum Cina (Chinese law), variasi dari tradisi Civilian, di dalam struktur, jika tidak dalam isi, dan akan terjepit di antara lapisan bawah hukum tradisional dan hukum Cina/civilian pada lapisan atas. (Esin Örücü, 2000 : 23) Secara hipotesis, hal itu yang menyebabkan norma lokal dan nilai-nilai atau konsep-konsep yang berkarakter Pancasila lebih banyak tidak dimengerti daripada nilai-nilai dan konsep-konsep hukum Barat, yang nota bene mewadahi kepentingan masyarakat industri.

Hukum Nasional tidak dapat disangkal dipengaruhi oleh warisan teorisasi hukum Barat (heritage of Western legal theorizing). Maksudnya bukan sekadar warisan hukum kolonial, namun dibangun dan dikembangkan atas dasar ilmu hukum Barat (Western jurisprudence) entah civil law atau common law system. Dalam kaitan dengan jurisprudence sebagai warisan hukum Barat, William Twining menegaskan bahwa :

general jurisprudence, work exclusively within the Western legal tradition. Their perspective is generally secular and they pay little or no attention to religion other than Christianity or to non-Western culture and traditions.

and related to this, almost all of Western jurisprudence has focused on state law, especially the domestic (municipal) law of sovereign, industrialised nation state. (William Twining, 2009 : 11-12)

Sejak mahasiswa kuliah pada semester awal, pertama kali sudah diajarkan ilmun hukum (jurisprudence) utamanya Barat modern, yang sama sekali tidak mengandung warisan pemikiran hukum lokal, khususnya Pancasila. Hal tersebut menyebabkan arsitektur hukum Nasional meskipun berkarakter sistem hukum campuran (mixed legal system), namun variannya didominasi tradisi hukum Barat, 
baik dalam area hukum publik maupun hukum privat. Variasi hasil pertemuan sistem hukum itu, menurut Esin Örücü (2000 : 27), dapat terjadi pada tingkatan ide, konsep, dan solusi serta pada tingkatan struktur, institusi, dan metode. Transplantasi hukum Barat pada tingkatan ide, konsep, dan solusi atau tingkatan struktur, institusi, dan metode dianggap lebih tepat dimaknai berdasarkan ajaran atau doktrin warisan hukum Barat yang dikemas dalam istilah ilmu hukum (jurisprudence), baik tataran dogmatik hukum (legal dogmatic), teori hukum (legal theory), atau filsafat hukum (legal philosophy). Itu sebabnya, teori hukum dan filsafat hukum Pancasila tidak muncul, alih-alih dalam proses pembentukan hukum dan penegakan hukum, dalam kurikulum pendidikan hukum pun tidak ditemukan. Sehingga, ratio legis dari suatu peraturan hukum atau asas hukum Nasional lebih mudah dicari dalam pemikiran-pemikiran hukum Barat daripada Pancasila. Persoalan yang kemudian muncul dan dihadapi bangsa Indonesia, yaitu problem kemampuan asas hukum Barat menjembatani cita-cita sosial dan peraturan hukum yang dibentuk. Pembentukan peraturan hukum melalui transplantasi dapat dilakukan dengan alasan untuk perubahan sosial (social change) di Indonesia. Persoalannya, apakah harus meninggalkan atau menanggalkan norma lokal dan Pancasila?

Realitas ini tidak hanya menjelaskan kegagalan mengintegrasikan nilainilai atau norma-norma lokal dan Pancasila ke dalam jaringan global yang lebih luas melalui pendekatan teoritis dari hukum, namun juga mengutarakan kekalahan hukum lokal dan Pancasila dalam persaingan nilai dan norma ketika berhadapan dengan hukum Barat.

\section{Contoh Bentuk Transplantasi Hukum Asing dalam UU Pemerintahan Daerah}




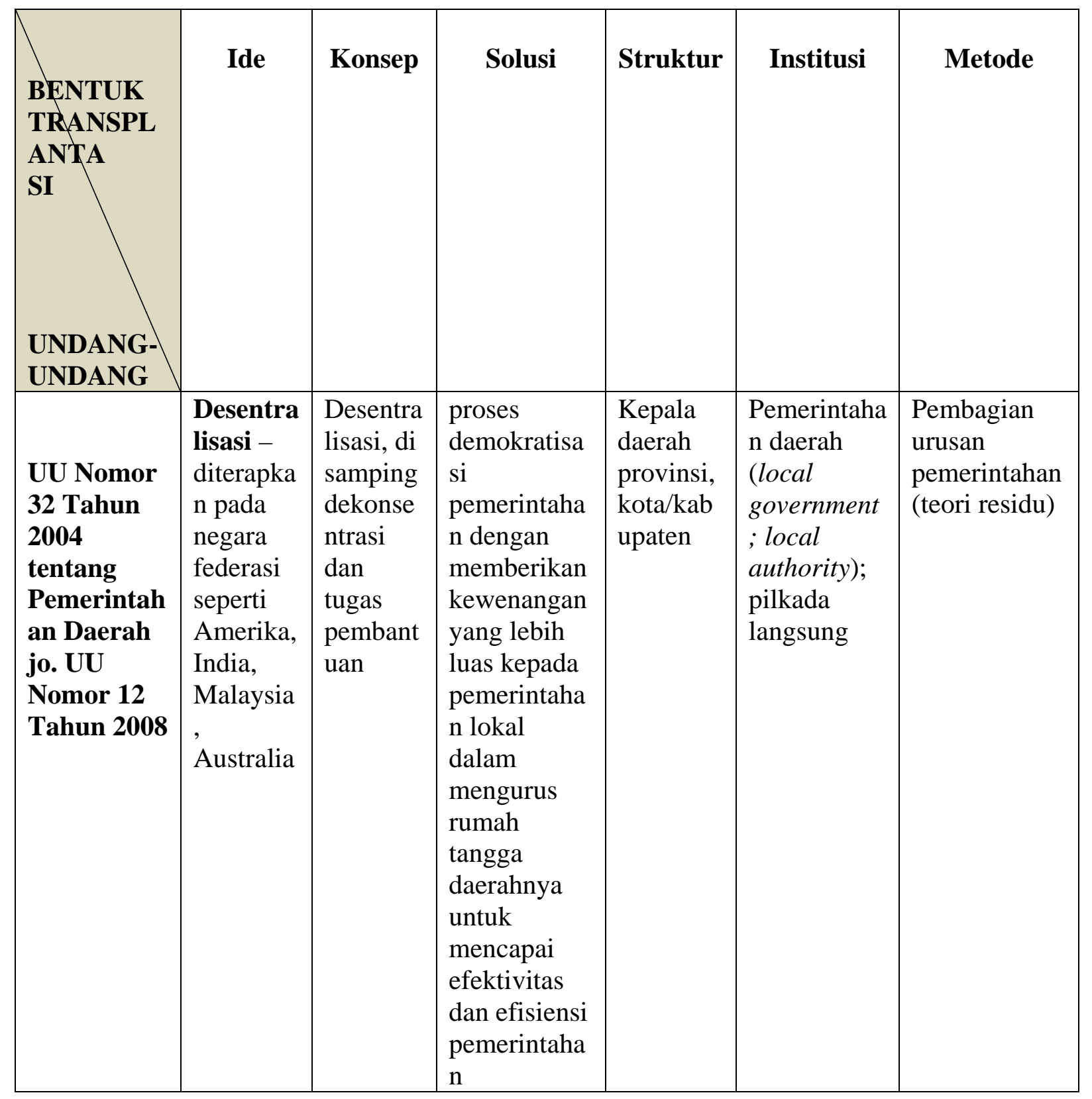

\section{Konvergensi Hukum ke Depan}

Berdasarkan pandangan instrumentalisme (instrumentalism), suatu nilai atau ideologi itu berguna ditentukan atas dasar pada berfungsi atau berpengaruhnya secara efektif dalam memenuhi tuntutan sosial, politik, dan ekonomi kehidupan berbangsa. Keberadaan secara aktual yang menentukan 
instrumental (berpengaruh)-nya suatu nilai atau ideologi, bukan sekadar pengakuan secara yuridis-konstitusional. Berdasarkan pandangan ini, lunturnya atau diabaikannya hukum lokal dan nilai-nilai Pancasila dalam kehidupan sosial, politik, dan ekonomi menandai bahwa ada persoalan terhadap berfungsinya Pancasila dalam kehidupan bangsa Indonesia. Lebih dari itu, Pancasila nyaris menjadi tidak instrumental. Hal itu dapat disebabkan mulai dari ketidakpahaman bangsa terhadap Pancasila sampai kekalahan Pancasila bersaing di rumah sendiri, yaitu dalam tertib kehidupan bangsa, khususnya peraturan perundang-undangan, mulai dari Konstitusi sampai peraturan daerah. Apabila demikian, maka pertanyaannya, yaitu mengapa bangsa Indonesia tidak paham terhadap Pancasila ? Nilai-nilai yang ideologis ke-Indonesia-an itu tergusur lazimnya karena digantikan oleh nilai-nilai ideologi lain yang dianggap lebih fungsional, misalnya dari nilainilai agraris-komunal ke industrial-individual, dari ekonomi kerakyatan ke liberalkapitalistis. Kehidupan bangsa Indonesia memang tidak hanya dilingkupi dan diatur oleh hukum atau peraturan perundang-undangan, namun juga agama, komitmen-komitmen politik, dan keyakinan-keyakinan lainnya, sehingga ideologi itu menjadi penting (William Twining, 2009 : 8) Sehingga, tergerusnya Pancasila sebagai ideologi hukum oleh ide-ide hukum lain menjadi persoalan penting juga.

Sebenarnya ketika peraturan perundang-undangan, termasuk Konstitusi mencerminkan sepenuhnya nilai-nilai atau ideologi Pancasila, maka sesungguhnya tidak perlu dikhawatirkan terjadinya pengabaian terhadap Pancasila. Sebab, persoalannya tinggal penegakan hukum. Namun, apabila pada tingkatan peraturan perundang-undangan saja nilai-nilai atau ideologi Pancasila sulit dideteksi keberadaannya, maka tidak ada jaminan sama sekali nilai-nilai Pancasila dapat instrumental (berpengaruh) dalam pergaulan hidup berbangsa dan bernegara. Oleh karena itu, pekerjaan besar Indonesia, yaitu membangun kembali pemahaman terhadap Pancasila dan pengembangan ide, konsep, dan solusi maupun struktur, institusi, dan metode yang mencerminkan Pancasila dalam peraturan perundang-undangan. Persoalannya lebih dari sekadar mengisi Konstitusi Indonesia dengan materi muatan Pancasila. Sebab, hal itu niscaya didahului pengembangan, bahkan pembentukan teori-teori normatif, seperti teori- 
teori keadilan dan hak berbasis Pancasila. Itu artinya, Pancasila masuk dalam studi-studi mengenai “jurisprudence as activity of theorizing” (lihat William Twining, 2009 : 9) Dalam konteks inilah, Pancasila perlu menjadi bagian dalam “jurisprudence”, bukan sekadar pelajaran (mata kuliah) Pancasila yang belum terkoneksi secara konseptual/teoritis dengan "jurisprudence”.

Bangsa Indonesia telah bersepakat bahwa Pancasila sebagai dasar filosofis dan ideologis, di samping dasar negara dan sumber dari segala sumber hukum negara. Sehingga, Pancasila harus selalu berpengaruh dalam kehidupan bangsa dan negara. Berdasarkan posisinya sebagai dasar negara, dasar filosofis, dan dasar ideologis, serta sumber dari segala sumber hukum negara, maka Pancasila bukan suatu instrumen (alat) untuk mencapai tujuan Nasional Indonesia sebagai bangsa yang merdeka, meskipun sering dalam kehidupan keseharian diinstrumentalisasi (difungsikan sebagai alat) untuk kepentingan-kepentingan pragmatis. Akibat instrumentalisasi terhadap Pancasila menjadikan validitasnya ditentukan oleh keberhasilan aksi dalam pencapaian tujuan penggunanya. Ketika Pancasila tidak berhasil mencapai tujuan yang diharapkan penggunanya, maka menjadikan Pancasila kehilangan validitasnya.

Pancasila niscaya menjadi kategori validitas (keabsahan) filosofis dan ideologis peraturan perundang-undangan, termasuk Konstitusi. Sehingga, peraturan perundang-undangan, termasuk Konstitusi itu yang menjadi instrumen pencapaian tujuan negara (alinea ke-4 UUD 1945) dan berbagai tujuan pragmatis kehidupan berbangsa dan bernegara, yang selalu didasari Pancasila. Dalam hal ini, instrumentalisasi Konstitusi juga untuk tujuan pemahaman dan implementasi nilai-nilai Pancasila itu sendiri dalam berbagai bidang sosial, politik, dan ekonomi.

Pancasila dan Konstitusi tidak dapat disangkal "hidup” dalam ruang yang tidak hampa dan kedap pengaruh. Globalisasi yang meruntuhkan sekat antara yang internasional dan domestik karena hubungan-hubungan internal dan eksternal tidak lagi menjadi jelas sebagai kekuatan utama di balik perubahanperubahan sosial, ekonomi, dan politik yang tengah menentukan kembali masyarakat modern dan tatanan dunia (Budi Winarno, 2007 : 13), sehingga 
Pancasila harus berhadap-hadapan dengan kekuatan dan transformasi itu. Persoalannya adalah ketika Konstitusi dan peraturan perundang-undangan yang ada di bawahnya dipergunakan sebagai instrumen perubahan sosial (social change) menyesuaikan dengan transformasi sosial, ekonomi, dan politik masyarakat modern pada satu sisi dan Pancasila sebagai dasar filosofis dan ideologis negara pada sisi lain menimbulkan persaingan. Persaingan ini tidak dapat dihindari karena globalisasi memang telah membuat negara tidak lagi dapat menjalankan fungsi yang benar-benar otonom. (Budi Winarno, 2007 : 11) Pertanyaannya, yaitu akankah Pancasila memenangkan persaingan itu ?

Keberhasilan memenangkan persaingan itu sangat bergantung tidak saja pada Majelis Permusyawaratan Rakyat yang memiliki ruang untuk mengubah Konstitusi dan Dewan Perwakilan Rakyat yang memiliki kekuasaan membentuk undang-undang serta Presiden yang memiliki hak mengajukan dan memberi persetujuan, serta mengesahkan rancangan undang-undang, namun juga bergantung pada komitmen masyarakat untuk menerima atau meresistensi (sebagian atau seluruh) arus besar perubahan itu. Oleh karena itu, pada tingkatan undang-undang perlu diadakan "undang-undang harmonisasi” yang mensyaratkan langkah-langkah tertentu, yang secara substantif menjamin penghormatan dan perhatian terhadap nilai-nilai Pancasila dan norma-norma masyarakat lokal. Sehingga, ketika harus meloloskan dominasi ide, konsep, dan solusi atau institusi, struktur, dan metode hukum asing, khususnya hukum Barat dalam pembentukan hukum, memiliki rasionalitas yang memadai. Kecuali, bangsa Indonesia merelakan nilai-nilai Pancasila tererosi secara dominan oleh nilai-nilai asing, baik dalam wujud ide, konsep, dan solusi maupun institusi, struktur, dan metode hukum.

\section{Simpulan}

1. Transplantasi atau difusi hukum dari Western law (hukum Barat), khususnya civil law system ke dalam tata hukum dan tata kehidupan masyarakat Indonesia muncul dalam berbagai bentuk berdasarkan kategori Esin Örücü, dalam pengertian ada kombinasi 
kompleks di satu sisi, dan sederhana di sisi lain. Western law yang ditransplantasikan itu di samping civil law system, juga berasal dari common law system, yang mengalami harmonisasi dalam bentuk konsonansi maupun disonansi dengan hukum adat atau lokal, hukum islam, dan nilai-nilai Pancasila.

2. Keniscayaan pemahaman terhadap Pancasila dan pengembangan ide, konsep, dan solusi maupun struktur, institusi, dan metode hukum yang mencerminkan nilai-nilai Pancasila dalam peraturan perundang-undangan. Persoalannya lebih dari sekadar mengisi Konstitusi Indonesia dengan materi muatan Pancasila. Sebab, hal itu niscaya didahului pengembangan, bahkan pembentukan teoriteori normatif, seperti teori-teori keadilan dan hak berbasis nilainilai Pancasila. Itu artinya, Pancasila masuk dalam studi-studi mengenai “jurisprudence as activity”.

\section{VI.Saran}

1. Transplanatsi atau difusi hukum perlu mempertimbangkan hukum adat atau hukum lokal, dan nilai-nilai Pancasila sebagai rujukan moral hukum karena posisinya sebagai sumber dari segala sumber hukum;

2. “Tailor-made model” niscaya dilakukan dalam kondisi munculnya ketidaksepadanan antara model (asing) dan resipien (hukum lokal dan Pancasila) sekalipun. Secara teoritis, perbedaan bukan halangan untuk melakukan harmonisasi.

\section{DAFTAR PUSTAKA}

B. Arief Sidharta. tanpa tahun. "Pancasila sebagai Filsafat Bangsa Indonesia".

Backer, Larry Catá. 2007. "Harmonizing Law in an Era of Globalization Convergence, Divergence, and Resistance : An Introduction and Analysis”, dalam Larry Catá Backer (ed), Harmonizing Law in an Era of Globalization - Convergence, Divergence, and Resistance : An Introduction and Analysis, Durham, North Carolina, Carolina Academic Press. 
Benda-Beckmann, Franz von; Benda-Beckmann, Keebet von; and Griffiths, Anne, “Mobile People, Mobile Law: An Introduction”, dalam Franz nvon BendaBeckmann, Keebet von Benda-Beckmann, dan Anne Griffiths (ed.), Mobile People, Mobile Law, Expanding Legal Relations in a Contracting World, England, Ashgate Publishing Limited.

Budi Winarno. 2007. Globalisasi \& Krisis Demokrasi. Jakarta:Buku Kita.

Cotterrell, Roger. 2006. Law, Culture, and Society, England: Ashgate.

Garner, Bryan A. (ed.). 2004. Black's Law Dictionary, Eight Edition, St Paul, USA, West.

Lomio, J. Paul; Spang-Hanssen, Henrik S. \& Wilson, George D., 2011, Legal Research Methods in a Modern World: a Coursebook, Copenhagen Denmark, DJØF Publishing.

Örücű, Esin, "Critical Comparative Law: Considering Paradoxes for Legal Systems in Transition”, Vol.4.1, June 2000, Netherlands Comparative Law Association, www.ejcl.org/41/art41-1.html, diunduh 3 Oktober 2012

Stuart, Christopher. 2007. "From 'Mother of the World' to the 'Third World' and Back Again : The Harmonization Cycle Between Islam and the Global Economy”, dalam Larry Catá Backer (ed), Harmonizing Law in an Era of Globalization - Convergence, Divergence, and Resistance : An Introduction and Analysis, Durham, North Carolina, Carolina Academic Press.

Twining, William. 2009. General Jurisprudence: Understanding Law from a Global Perspective (Law in Context), Cambridge, Cambridge University Press.

Wacks, Raymond. 2009. Understanding Jurisprudence, An Introduction to Legal Theory, second edition, New York, Oxford University Press.

Watson, Alan. 1993. Legal Transplants, an Approach to omparative Law, Athens and London, The University of Georgia Press. 